\title{
Atrial myxoma presenting as abdominal pain: an unusual association
}

\author{
Faisal Inayat, ${ }^{\oplus}$ Amna Hussain, ${ }^{1}$ Iqra Riaz, ${ }^{2}$ Hafeez UI Hassan Virk ${ }^{2}$
}

'Allama Iqbal Medical College, Lahore, Pakistan

${ }^{2}$ Einstein Medical Center, Philadelphia, Pennsylvania, USA

Correspondence to Dr Faisal Inayat, faisalinayat@hotmail.com

Accepted 1 February 2019

\section{DESCRIPTION}

A 57-year-old obese man presented to our medical centre with abdominal pain for 12 hours. The pain was severe, diffuse, crampy in nature, marked in the lower left abdomen, non-radiating and aggravated after eating and drinking. It was associated with diaphoresis and one episode of non-bloody, non-bilious vomiting. He was not under therapy with any medications and denied recent hospitalisation. He reported 'many years' of alcohol intake and cocaine abuse. His most recent tobacco use was in 2005. On admission, the patient was afebrile and haemodynamically stable. However, his ECG demonstrated atrial fibrillation with controlled heart rate. Laboratory studies revealed serum lactate $4.8 \mathrm{mmol} / \mathrm{L}$ (normal, $0.5-1 \mathrm{mmol} / \mathrm{L}$ ) and white cell count $10.07 \times 10^{9} / \mathrm{L}$ (normal, $4.5-11.0 \times 10^{9} / \mathrm{L}$ ). Given the suspicion of bowel ischaemia in the presence of abdominal pain, lactataemia and atrial fibrillation, he underwent urgent CT abdomen. It revealed a $5.0 \times 5.0 \times 4.5 \mathrm{~cm}$ hypodense lesion in the left atrium (figures 1 and 2).

Transthoracic echocardiography showed a large $4 \times 5 \mathrm{~cm}$ left atrial mass, which extended from interatrial septum to mitral annular plane (figures 3 and 4). The left and right ventricular sizes and systolic function were normal. The CT and echocardiographic features of the lesion were strongly suggestive of an atrial myxoma. Therefore, curative resection was planned. Cardiothoracic surgery recommended left cardiac surveillance catheterisation. It ruled out obstructive coronary artery disease. Subsequently, the patient underwent an uneventful excision of the mass, which was found adherent to the floor of the atrium, without an involvement of pulmonary veins or mitral valve.

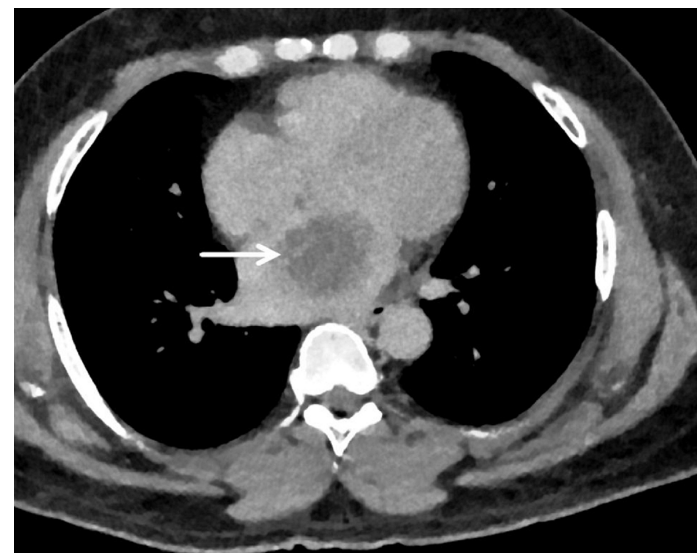

Figure 1 Transverse section of CT chest showing left atrial mass (arrow)

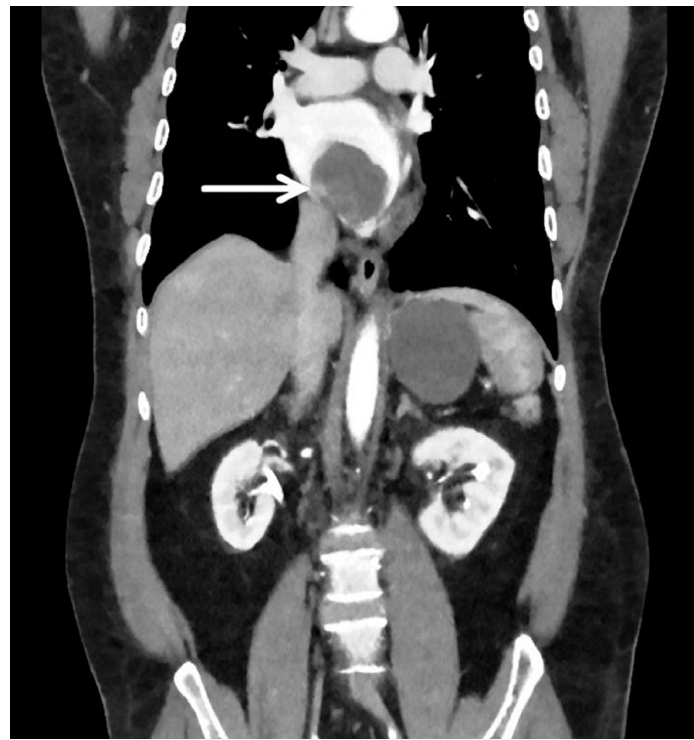

Figure 2 Coronal section of CT chest showing left atrial mass (arrow).

The gross examination of the resected specimen showed a $5 \mathrm{~cm}$ ovoid mass (figure 5). The findings of histopathological examination confirmed the diagnosis of myxoma. Thereafter, he underwent maze procedure and left atrial appendage closure for atrial fibrillation, the abnormality encountered at the time of his current presentation. The patient recovered well after the surgery. After 3 days of postoperative monitoring, he was discharged from the hospital in a stable condition. At the 1-month follow-up, he did not report recurrence of his abdominal pain. He continues to do well thus far.

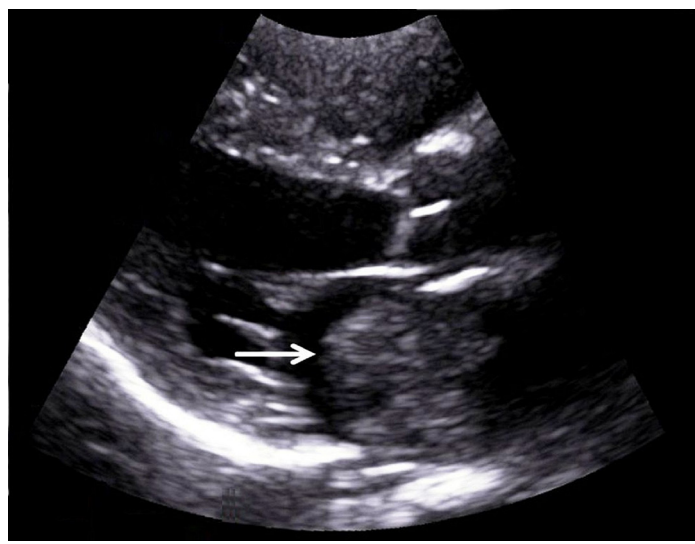

Figure 3 Parasternal long axis view of the heart in transthoracic echocardiography showing left atrial mass (arrow). 


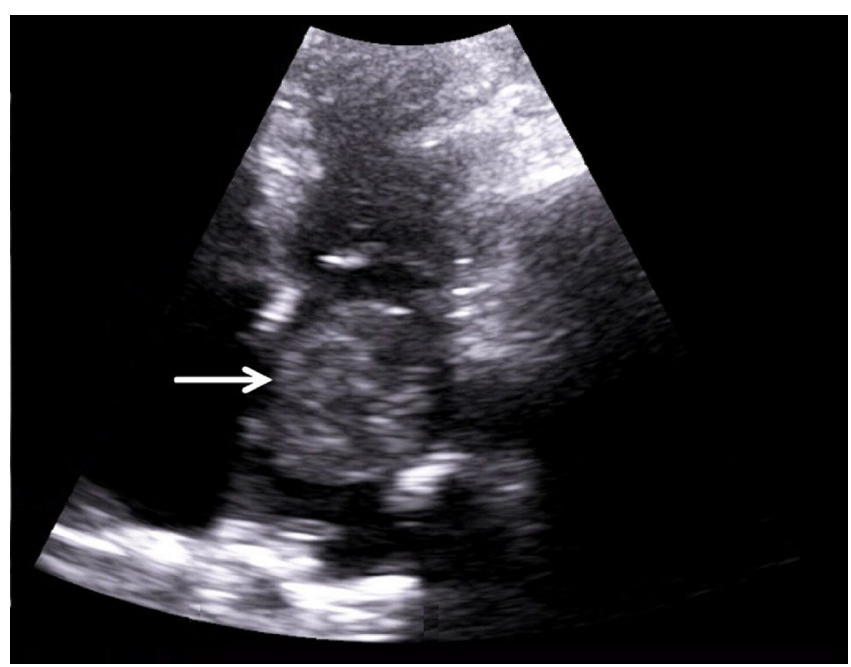

Figure 4 Apical four chamber view of the heart in transthoracic echocardiography showing left atrial mass (arrow).

In 1959, Effert and Domanig first coined the echocardiographic features of atrial myxoma. ${ }^{1}$ Since then, a remarkable increase in the global incidence of this disease has been observed. However, this benign cardiac tumour still remains an exceedingly rare clinical entity with an incidence of $0.14 \%$ and prevalence of $<5$ in 10000 . The mean age of initial clinical presentation ranges from 30 to 60 years (sporadic cases: 56 years; familial disease: 25 years). In prior research, slight female gender predominance has been described, with the female-to-male ratio of $2.7: 1.0 .^{2}$ This tumour predominantly involves the left atrium but reports of right atrial as well as septal involvement are also available. ${ }^{2}$

In a French study, the typical triad of presentation comprised the symptomatology of mitral valve obstruction (67\%), embolism (29\%) and constitutional symptoms, including fever, weight loss and fatigue $(34 \%){ }^{3}$ Several extracardiac manifestations of this lesion have also been reported in the published medical literature. Acute psychosis, Carney complex, acromegaly, multiple mononeuropathies, sepsis and disseminated intravascular coagulation have been documented as unusual associations in patients with atrial myxoma. ${ }^{4}$ However, the present patient was unique in this regard as he did not develop any of the above-mentioned

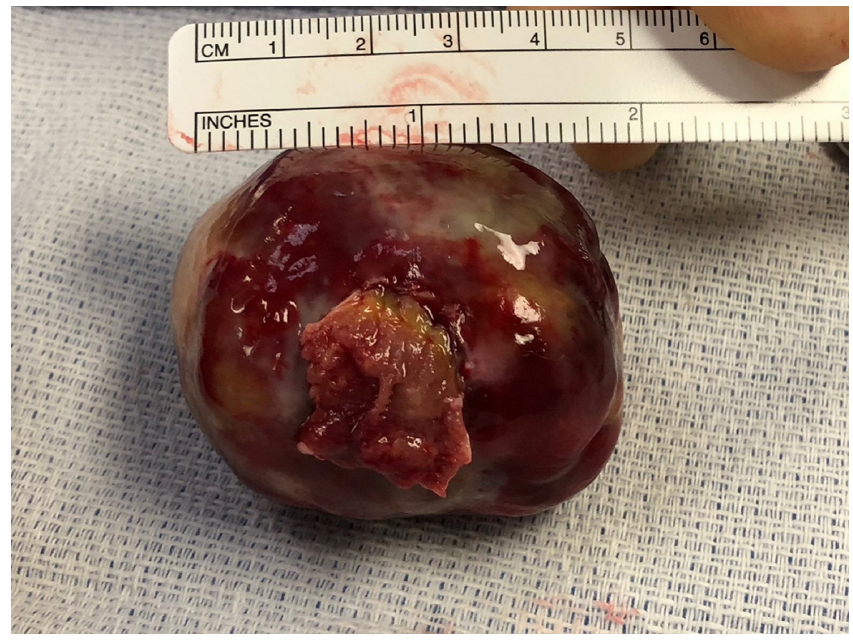

Figure 5 The gross morphology of the post-resection specimen demonstrating an ovoid-shaped left atrial myxoma, measuring $4 \times 5 \mathrm{~cm}$. symptoms or signs. To the best of our knowledge, the current report represents the first case of an atrial myxoma presenting as abdominal pain.

We attribute the abdominal pain in our patient to the microemboli-related mesenteric ischaemia, leading to lactatemia and pain. In a vast majority of cases, emboli generally lodge in the superior mesenteric artery, culminating in acute onset of pain. The major predisposing factors for this phenomenon include pre-existing cardiomyopathy, atrial fibrillation, recent angiography, underlying vasculitis or valvular disorders. Abdominal pain is the most common clinical presentation of emboli-associated mesenteric ischaemia and the present patient also had atrial fibrillation. Additionally, another probable explanation worth mentioning is that the myxoma is a very active tumour that secretes interleukin-6, leading to constitutional symptoms like fever, headaches and fatigue. ${ }^{5}$ Therefore, it is a possibility that abdominal pain may also be caused by a similar secretary mechanism.

Over half a century ago, this lesion frequently posed a diagnostic challenge due to the varied clinical features and close mimicking of valvular disease. However, after the advent of echocardiography, the diagnosis can be established conveniently. The diagnostic modality of choice is a transesophageal echocardiography due to its ability to identify the size, site, attachment, and mobility. It also grossly demarcates the myxoma from vegetation or a thrombus. Coronary angiography and MRI may also be performed in difficult-to-diagnose cases or to rule out other cardiac abnormalities. ${ }^{4}$ With regard to the management, complete surgical excision is the treatment of choice with excellent clinical outcomes. Although a vast majority of myxoma lesions are benign, curative resection is required to avoid devastating complications in these patients. ${ }^{4}$

The present report describes a patient with left atrial myxoma who presented with abdominal pain, whose symptoms resolved after surgical excision of the tumour. This case is unusual in terms of its presentation, leading to the unexpected diagnosis of an atrial myxoma, which can be often misdiagnosed or confused with other medical conditions.

\section{Learning points}

- Physicians should maintain a high index of clinical suspicion for extracardiac manifestations of atrial myxoma as its presence can be heralded by non-specific constitutional symptoms.

- Non-specific extracardiac symptoms, such as abdominal pain, may contribute to misdiagnosis of this rare but totally treatable atrial tumour.

Contributors $\mathrm{Fl}$ designed the study, performed the literature review, drafted the manuscript, revised the manuscript critically for important intellectual content and gave the final approval for the version published. AH performed the literature, review and drafted the manuscript. IR contributed to and reviewed the manuscript. HUHV reviewed the manuscript and suggested pertinent modifications.

Funding The authors have not declared a specific grant for this research from any funding agency in the public, commercial or not-for-profit sectors.

Competing interests None declared.

Patient consent for publication Obtained.

Provenance and peer review Not commissioned; externally peer reviewed.

\section{REFERENCES}

1 Effert S, Domanig E. The diagnosis of intra-atrial tumours and thrombi by the ultrasonic echo method. Ger Med Mon 1959;4:1-3. 
2 Aggarwal SK, Barik R, Sarma TC, et al. Clinical presentation and investigation findings in cardiac myxomas: new insights from the developing world. Am Heart J 2007; 154:1102-7.

3 Pinede L, Duhaut P, Loire R. Clinical presentation of left atrial cardiac myxoma. A series of 112 consecutive cases. Medicine 2001;80:159-72.
4 Thyagarajan B, Kumar MP, Patel S, et al. Extracardiac manifestations of atrial myxomas. J Saudi Heart Assoc 2017;29:37-43.

5 Mendoza CE, Rosado MF, Bernal L. The role of interleukin- 6 in cases of cardiac myxoma. Clinical features, immunologic abnormalities, and a possible role in recurrence. Tex Heart Inst J 2001;28:3-7.

Copyright 2019 BMJ Publishing Group. All rights reserved. For permission to reuse any of this content visit https://www.bmj.com/company/products-services/rights-and-licensing/permissions/

BMJ Case Report Fellows may re-use this article for personal use and teaching without any further permission.

Become a Fellow of BMJ Case Reports today and you can:

- Submit as many cases as you like

- Enjoy fast sympathetic peer review and rapid publication of accepted articles

- Access all the published articles

Re-use any of the published material for personal use and teaching without further permission

For information on Institutional Fellowships contact consortiasales@bmjgroup.com

Visit casereports.bmj.com for more articles like this and to become a Fellow 